\title{
O conflito como realidade e desafio cultural no exercício da gerência do enfermeiro*
}

\author{
CONFLICTASAREALITYAND ACULTURAL CHALLENGE INTHE \\ PRACTICE OF NURSES' MANAGEMENT
}

\author{
EL CONFLICTO COMO REALIDAD Y DESAFÍO CULTURAL, \\ EN EL EJERCÍCIO DE LA GERENCIA DEL ENFERMERO
}

\section{Adelina Giacomelli Prochnow', Joséte Luzia Leite", Alacoque Lorenzini Erdmann"', Maria Auxiliadora Trevizan'v}

\begin{abstract}
Extraído da tese "O exercício da gerência do enfermeiro: cultura e perspectivas interpretativas", Escola de Enfermagem Anna Nery, Universidade Federal do Rio de Janeiro, 2004.

I Enfermeira. Doutora em Enfermagem pela Escola de Enfermagem Anna Nery, Universidade Federal do Rio de Janeiro (EEAN/ UFRJ). Professora Assistente da Universidade Federal de Santa Maria, Santa Maria, RS, Brasil.

agp.sma@terra.com.br.

II Enfermeira. Professora Titular Emérita da Universidade Federal do Estado do Rio de Janeiro (UFRJ). Rio de Janeiro, RJ, Brasil. joluzia@gmail.com

III Enfermeira. Doutora em Filosofia da Enfermagem. Professora Titular do Departamento de Enfermagem e Programa de Pós-Graduação em Enfermagem da Universidade

Federal de Santa Catarina (UFSC) Florianópolis, SC Brasil.alacoque@ newsite.com.br

O exercício da gerência do enfermeiroé permeado de conflitos que podem ser interpretados pelos referenciais de cultura. O presente estudo tem como objetivo denotar especificidades culturais, analisadas segundo a Teoria Interpretativa da Cultura de Geertz, que se expressam como conflitos no âmbito da gerência do enfermeiro num Hospital Universitário. Os resultados denotam a incorporação de elementos ideológicos e de mecanismos de controle e de poder, que manifestam sua origem na forma de organização do trabalho. Percebe-se a efetivação de políticas alicerçadas em valores da própria profissão. As práticas exercidas destacam uma construção cultural que elucida algumas compreensões dos processos cognitivos, sociais e comportamentais, pois estes organizam as interpretações e as respostas para os eventos da prática gerencial do enfermeiro. Os resultados deste estudo apontam para a importância da cultura organizacional no exercício da gerência na enfermagem diante das incertezas laborais, na complexidade do ambiente hospitalar.
\end{abstract}

IV Enfermeira. Professora Titular da Escola de Enfermagem de Ribeirão Preto, Universidade de São Paulo (EERP/USP) Ribeirão Preto, SP, Brasil.

trevizan@eerp.usp.br

\section{RESUMO}

\section{DESCRITORES}

Supervisão de enfermagem.

Cultura organizacional.

Administração hospitalar.

\section{ABSTRACT}

The practice of nurses' management is permeated by conflicts that can be interpreted through culture references. The objective of this study is to denote cultural specificities, analyzed according to Geertz's Cultural Interpretative Theory, that are expressed as conflicts in the scope of nurses' management at a University Hospital. The results denoted the incorporation of ideological elements and mechanisms of control and power, whose origin can be seen in the way in which the work is organized. The application of policies based on the profession's very values was observed. Practices highlight a cultural construction that elucidates some understandings regarding cognitive, social and behavioral processes, because they organize the interpretations and the answers to the events of nurses' practices in management. The results of this study point out the importance of organizational culture in the practice of Nursing management in the face of labor uncertainties in the complexity of a hospital environment.

\section{KEY WORDS}

Nursing, supervisory. Organizational culture. Hospital administration.

\section{RESUMEN}

El ejercicio de la gerencia del enfermero es perneado de conflictos que pueden ser interpretados por los referenciales de cultura. El presente estudio tiene como objetivo denotar especificidades culturales, analizadas según la Teoría Interpretativa de la Cultura de Geertz, que se expresan como conflictos en el ámbito de la gerencia de enfermero en un Hospital Universitario. Los resultados denotan la incorporación de elementos ideológicos y de mecanismos de control y de poder, que manifiestan su origen en la forma de organización del trabajo. Se percibe la efectividad de políticas basadas en valores de la propia profesión. Las prácticas ejercidas destacan una construcción cultural que elucida algunas comprensiones de los procesos cognitivos, sociales y de comportamientos, pues estos organizan las interpretaciones y las respuestas para los eventos de la práctica gerencial del enfermero. Los resultados de este estudio apuntan para la importancia de la cultura organizacional en el ejercicio de la gerencia en la enfermería delante de las inseguridades laborables, en la complejidad del ambiente hospitalario.

\section{DESCRIPTORES}

Supervisión de enfermería. Cultura organizacional. Administración hospitalaria. 


\section{INTRODUÇÃO}

$\mathrm{Na}$ interface entre múltiplos saberes da enfermagem, cotidianamente no exercício da gerência, o enfermeiro se depara envolvido com conflitos uma vez que conduz múltiplas relações de uma equipe com diversas categorias profissionais. Nestas circunstâncias trabalha com situações complexas do sistema produtivo e busca respeitar a historicidade e diversidade de interesses.

A habilidade de promover os ajustes e intervenções nas ações entre os atores sociais é um processo que necessita da compreensão do fenômeno em voga para o desenvolvimento da capacidade de negociação gerencial.

Para tanto, este estudo tem como objetivo denotar especificidades culturais, analisadas segundo a Teoria Interpretativa da Cultura de Geertz, que se expressam como conflitos no âmbito da gerência do enfermeiro num Hospital Universitário. Pretende-se com o mesmo, possibilitar o aprimoramento de nossos conhecimentos e capacidades de enfrentamento diante das incertezas laborais na complexidade do ambiente hospitalar.

\section{BREVE \\ FUNDAMENTACÃO TEÓRICA}

A teoria de Geertz sustenta-se nos parâmetros humanísticos, interpretativos, embasados na hermenêutica, na crença de que os textos ou produção intelectual são construções fundamentadas em uma atmosfera de diversidade, pluralismo e conflito, o que é intelectualmente vital para uma disciplina ${ }^{(1)}$.

A palavra hermenêutica sugere o processo de trazer uma situação ou uma coisa, da inteligibilidade à compreensão, ou seja, tornar compreensível. A hermenêutica fornece interpretações válidas moldadas pelo curso das interrogações. Orienta-se não só em como obter interpretações válidas, mas também, na natureza ou dinâmica da própria compreensão ${ }^{(2)}$.

Clifford Geertz, antropólogo norte-americano da segunda metade do século XX, contribuiu com a teoria social e cultural, que não visava apenas a própria teoria e práticas antropológicas. Ele é considerado o criador da antropologia interpretativa ou hermenêutica, uma das vertentes da antropologia contemporânea ${ }^{(3-5)}$. Foi considerado como proponente e defensor do movimento em prol da cultura, entendida como um sistema simbólico ${ }^{(1,6)}$.

O conhecimento antropológico surge das práticas simbólicas e dos discursos embasados nas diferenças e suas fronteiras ${ }^{(7)}$. Assim, a busca do conhecimento pela antropo- logia interpretativa ocorre pelo esforço de entender o outro - o diferente - que leva as pessoas a verem-se como os outros as vêem. Para utilizar a ciência social interpretativa, em geral, é importante estar ciente de que as incertezas e as ambigüidades fazem parte do processo de forma intensa, pois trocam as relações causais, cíclicas, por uma gama de tentativas de explicação, em um contexto particular, no qual surgirão inúmeras dificuldades desconhecidas. Sobre este delineamento, propõ $\mathrm{e}^{(8)}$ :

\section{interpreta suas experiências, e depois utilizamos os rela- tos daquelas interpretações para tirar algumas conclu- sões sobre expressão, poder, identidade, ou justiça, sentimo-nos, a cada passo, bem distantes de estilos-pa- drão de demonstração. Utilizamos desvios, encontramos por ruas paralelas...}

Seu trabalho analisa os entendimentos diferentes dos já estabelecidos culturalmente. Tais entendimentos o autor denomina hermenêutica que, adicionada da palavra cultural, define o que ele faz.

Assim, os temas de pesquisa, podem ser considerados grandes unidades de pensamento, porque se resumem em um número de símbolos interligados dentro das relações de significado.

Em face disso, cultura é uma ciência interpretativa, à procura do significado. $\mathrm{O}$ significado é construído e estabelecido socialmente, sendo essencialmente semiótico; portanto, surge de um contexto com sistemas entrelaçados de símbolos públicos interpretáveis $^{(4)}$. Como a análise da cultura transpõe o próprio corpo do objeto, ela conduz o pesquisador a iniciá-la com interpretações sobre o que se imagina que pretendem os informantes para, após, sistematizá-las como um fato natural.

As formas do saber são sempre e inevitavelmente locais, inseparáveis de seus instrumentos e de seus invólu$\operatorname{cros}^{(8)}$. Tal afirmativa leva ao aguçado sentido de que a antropologia sempre considera a história, o contexto da interrelação existente, de que aquilo que se vê depende do lugar em que foi visto; portanto, torna-se relevante sua contribuição na forma de se pensar a sociedade, o ser humano, seu saber na atualidade, denotando suas contribuições como ciência que proporciona uma arena de debate especulativo.

A gerência do cuidado de enfermagem pode ser vista por diferentes olhares, o que possibilita visualizar a sua unidade na totalidade e as suas várias dimensões e facetas, orientadas pelos sistemas simbólicos representativos das composições organizacionais dos serviços de saúde, cuja noção de pluralismo pode possibilitar visualizar as diferentes facetas desta arena social ${ }^{(9)}$. 
A cultura organizacional da enfermagem mostra unidades de pensamento, ou os símbolos interligados dentro das relações de significado que estruturam a dinâmica do trabalho realizado pelos profissionais de enfermagem.

O trabalho de enfermagem se constitui por relações múltiplas interativas do fazendo-pensando, o cuidando - educando - gerenciando - investigando como uma prática integrativa.

No cotidiano, a enfermagem brasileira tem se empenhado junto às instituições de saúde, para desenvolver as atividades administrativas inerentes à gerência das unidades, não mais como um trabalho subdividido, centrado nas funções, e sim, como trabalho articulado, integrado com os demais serviços, co-compartilhado, numa relação de troca e ajuda mútua, envolvendo os diversos atores presentes neste sistema de cuidado.

Neste cenário, o exercício da gerência como liderança de enfermagem é visualizada,

pelo modo de expressão do potencial de ser humano no exercício das relações participativas e interativas e na construção de novos saberes e práticas integrativas compartilhadas, que possibilitem a criação e recriação de valores que os tornam sujeitos críticos, reflexivos e transformadores da realidade social(10).

Seguindo este enfoque, o conceito de cultura ${ }^{(11)}$ é entendido como

um conjunto de - mecanismos de controle - planos, receitas, regras, instruções (o que os engenheiros de computação chamam de programas) - para governar o comportamento.

O mesmo autor complementa que o ser humano é, desesperadamente, dependente de tais programas culturais e de mecanismos de controle extragenéticos, para ordenar seu comportamento.

Outros autores compreendem a cultura como

tudo o que o homem adquire ou produz, com o uso de suas faculdades: todo o conjunto do saber e do fazer, ou seja, da ciência e da técnica e tudo o que com o seu saber e com o seu fazer extrai da natureza ${ }^{(12)}$.

Ou, ainda, toda cultura é um processo permanente de construção, desconstrução e reconstrução ${ }^{(13)}$, visto que nascem de relações sociais que são sempre desiguais. Vale esclarecer, segundo outro autor, que tudo o que faz parte puramente do privado, não faz parte da cultura ${ }^{(12)}$.

O transitar por diferentes espaços, no caso, o fato de o enfermeiro atuar em diversos campos da profissão constitui-se em possibilidades importantes para confrontar e rever ideologias que mantém assimetrias de poder, e o condena a ser vítima e algoz de sua própria prática ${ }^{(14)}$, ou mesmo, para tomar consciência dos diferentes modos de pensar e possi- bilidades de retomadas de atitudes construtivas para o avanço da profissão.

O conhecimento de sua prática gerencial, ante as contradições vividas e evidenciadas, motiva os enfermeiros para o estudo dos conflitos ou contradições sob diversos enfoques, tomando por base, principalmente, os novos conhecimentos teórico-filosóficos do campo da administração. Disso decorrem os diversos conceitos, modelos ou teorias que foram manifestados à luz do conhecimento científico sob as mais variadas proposições, interpretações e aplicações.

\section{MÉTODO}

Trata-se de uma pesquisa descritiva de caráter qualitativo, onde priorizamos o discurso dos entrevistados, como fonte de informação para a análise dos conflitos do enfermeiro no exercício gerencial.

Depreendendo que o material com que trabalhamos fundamenta-se a partir do diálogo interativo desenvolvido através de entrevistas, e partindo da premissa de que tudo que é dito é passível de ser submetido a análise e interpretação, norteamos o estudo a partir do enfoque de cultura $^{(1)}$ como as teias de significado que o ser humano teceu e nas quais ele se encontra e enxerga seu mundo, sempre procurando seu significado, a fim de obtermos a compreensão do objeto de estudo.

Realizamos a presente investigação num Hospital Universitário do interior do Estado do Rio Grande do Sul, certificado como de Ensino e caracterizado como de Porte IV, mediante comunicação prévia e devida autorização, seguindo os preceitos éticos para pesquisa que envolve seres humanos, conforme estabelece a Resolução 196/96 (Processo CEP n. 108/02) $)^{(15)}$.

Participaram deste estudo vinte e dois sujeitos, enfermeiros chefes de unidades de enfermagem de abril a setembro do ano de 2003. Os sujeitos da pesquisa foram selecionados de forma intencional, aos instituídos no cargo de chefe de unidade.

A coleta de dados foi realizada mediante a técnica de entrevista individual, tendo como instrumento um roteiro de temas referentes ao cotidiano gerencial do enfermeiro, no que tange as condições de trabalho, hábitos, desempenhos, enfrentamentos, percepções, regras, normas sistemáticas, crenças, tomada de decisões, e outros, com a finalidade de denotar especificidades culturais que pudessem ser compreendidas como conflitos no âmbito do exercício gerencial.

Os dados coletados foram gravados e transcritos na íntegra sendo posteriormente validados pelos partícipes. Os sujeitos estão identificados no texto com a letra $D$, seguida dos números de 1 a 22, correspondentes aos depoimentos efetivados. 
O processo analítico envolveu leituras e averiguações dos dados relevantes a fim de interpretar o fenômeno em voga, seguindo as etapas a fim de penetrar no próprio corpo do estudo ${ }^{(1)}$ que foram assim desenvolvidas:

- etapa 1: momento de desconstrução ou desmontagem de documentos a fim de traçar a curva do discurso social, interrogações, verificação dos processos naturais duradouros e grau de variação de significado, evidências subjetivantes, reconstrução da realidade - enxergar o significado das coisas a partir das determinações e especificidades estabelecidas pelo grupo social em si.

- etapa 2: interpretação (momento que procura sistematizar e descrever um significado mais abrangente dos dados, vinculando-os a outros conhecimentos) - realização da seleção e destaque dos elementos-chave de significado, percepção dos sentidos nos enunciados especificando as relações internas entre os elementos que caracterizam e descrevem o dito no discurso social, a fim de tornar explícito o conhecimento implícito.

- etapa 3: evidência e descrição do que o ato simbólico tem a dizer sobre ele mesmo.

\section{APRESENTAÇÃOE DISCUSSÃO DOS RESULTADOS}

Quanto aos resultados obtidos, verificamos que os conflitos no exercício da gerência do enfermeiro apareceram de forma eminente sob suas mais diferentes manifestações e refletem a complexidade do tipo de produção, no qual envolve desde os meios materiais até as tecnologias e conhecimentos incorporados. Desta forma, procuramos discernir e compreender os modos de ser e de atuar, a partir do discurso dos enfermeiros entrevistados.

Expor conflitos como uma realidade culturalmente construída significa investigar o exercício da gerência sob a perspectiva dos seus atores, incluindo intenções e encaminhamentos com diretrizes coletivas.

Através das falas dos entrevistados, percebe-se a incorporação de elementos ideológicos que manifestam sua origem na forma de organização do trabalho, e reportam à idéia de lealdade às instituições, de talento, de reconhecimento, de valores relacionados à questão moral como: responsabilidade, disciplina, engajamento, harmonia, comprometimento, valorização do ser humano, que resultam em um sentimento que demonstra afinco com o caráter religioso e militar, o que justapõe alguns mitos, que servem de base à sua prática. Entre tais falas:

A cópia da escala está sempre comigo. Na pasta do colégio, na bolsa, sabe? porque sempre tem alguém telefonando, pedindo, perguntando, solicitando. Daí, eu pego a escala, vou lá ver se o quadro está completo mesmo, para ver se não vai dar furo. É, não adianta (D 12).
Diante das imposições das decisões organizacionais, penso que, se vem de cima, elas reagem (os servidores subjugados a sua chefia), mas mandaram fazer, tem que ser feito (D4).

O compromisso e a dedicação expressa nos conduzem à analogia de interpretação, ou seja, é possível entender suas ações como uma missão, ressaltando o caráter ideológico incorporado na formação e socialização desses profissionais.

O desenvolvimento do conhecimento e experiência profissional não impede que a ideologia seja perpetuada e manifesta no comportamento da enfermeira, embora desvendada sua face oculta por meio de diversos trabalhos científi$\cos ^{(16-17)}$. Os dados obtidos nesse nosso estudo reafirmam que o trabalho administrativo do enfermeiro está caracterizado por uma ligação intrínseca da burguesia ao status da classe dominante, subjugada a parâmetros vinculados aos interesses do capital, ou seja, governamentais ${ }^{(16-17)}$. Assim, nosso discurso permanece hegemônico e demonstra a ligação com as raízes da profissão, o que denota um traço cultural próprio da categoria.

Quanto às considerações relativas a enfermagem, enquanto profissão, como altruística, heróica e santificadora ${ }^{(18)}$, consideramos que esta concepção, por muito tempo, dissimulou sua relação com os objetivos institucionais, junto aos quais ela estava ligada para à manutenção do status e do poder exercido pelas instâncias superiores. A enfermagem reproduzia a mesma faceta ante estes grupos e ante sua comunidade executante, o que denota a divisão de papéis na manutenção de uma elite que implementa e outra que executa as ações de enfermagem ${ }^{(19)}$.

Ao analisar as entrevistas dos profissionais, percebemos que, mesmo tendo conhecimento de que o mercado de trabalho está subordinado ao processo de valorização do capital, os depoentes se prestam a servir à ideologia dominante, admitindo sua atuação como subalterna ao poder médico, ainda hegemônico diante dos demais profissionais de saúde. É possível entender que isso ocorre pela indefinição do status-papel, manifesto através de uma crise de identidade. Desta forma, o serviço do enfermeiro contribui com uma função papel intermediária a qual associa uma atitude instrumental e instituída como natural ${ }^{(16-17)}$.

A formação da mentalidade dos enfermeiros está intrinsecamente subsidiada, docilizada e modelada pelo trabalho e pelo poder médico, impressa em estereótipos baseados na humildade, na obediência e no respeito à hierarquia, que conjugam subserviência, disciplina, honestidade, cumprimento de deveres, submissão/silêncio, devoção, espírito de servir, apesar de decorridos quase dois séculos da institucionalização dos hospitais e, conseqüentemente, da divisão social do trabalho hospitalar ${ }^{(20)}$. 
Uma das armadilhas ideológicas presentes no jogo entre competências e incompetências relativas a enfermeiros e médicos se estabelece no argumento de quem decide e manifesta segurança no processo decisório, ou seja, manifesta a simbologia de que quem decide é mais competente do que aquele que executa, pois este último tem menos segurança no que executa por que não intervêm no momento da concepção e por não decidir é considerado menos competente ${ }^{(21-22)}$. Com a incorporação desse entendimento pela enfermagem e pela sociedade, ambas acuadas pela hegemonia médica, o enfermeiro permanece preso num conformismo perante as rotinas e incongruências das atividades hospitalares.

Poderíamos justificar que as contradições são negadas, ou não são percebidas, entre os níveis de discurso e extradiscurso. Verificamos que, ante as atividades de gerenciamento, os profissionais consideram-se membros responsáveis pela estrutura do serviço, provedores da organização da seção de trabalho e responsáveis pelas relações interpessoais no grupo.

A condição para o exercício da gerência do enfermeiro é marcada pela incorporação de mecanismos de controle, conseqüentemente, de poder. Estes mecanismos caracterizam traços subjugados à história da profissão, que abarca tanto o domínio religioso e militar como sua coligação com o status das classes dominantes, portanto, relega os enfermeiros à subordinação e imposição da execução de tarefas ou ordens.

É pertinente salientar que a gerência é um instrumento de trabalho fundamental para a efetivação de políticas, talvez nesse meandro, seja possível construir um modelo assistencial alicerçado em valores adequados à cultura da própria profissão, organizado a partir da rede de saberes e das práticas que valorizam as multidimensões e a diversidade, para conseguir conviver, no cotidiano, com uma dinâmica complexa, alicerçada em contradições e paradoxos. Eis o que dizem os entrevistados:

Nós estamos aqui para trabalhar com o paciente, agilizar isso (D7).

Não adianta discutir, são normas, vem de cima, e tu tem que seguir essas normas, eu sou muito disciplinada, eu gosto de normas, rotinas, acho que ajuda a fazer nosso trabalho no dia-a-dia, eu não tenho problema nenhum em repassar (D21).

Esta constatação evidencia que o enfermeiro incorporou a racionalidade na organização do trabalho, assumindo de maneira automática e parcelar as atividades complexas do trabalho coletivo e intermediando relações entre os diferentes profissionais ${ }^{(23)}$.

Os dados dos depoentes re-enfatizam a idéia de que a efetiva contribuição da ação do enfermeiro, no exercício da gerência, se dá tanto na organização da unidade quanto no trabalho. O profissional-gerente é o ponto de referência, a direção, o condutor, o coordenador, o líder do grupo, sendo vital seu trabalho para o funcionamento administrativo da unidade.

Eis o que dizem os depoentes:

Ela tem um papel decisivo no sentido de personificar uma equipe, além dela ser a referência tanto de dentro para fora como de fora para dentro (D3).

Em tudo, porque, no momento que não têm, é como se eles perdessem, a equipe perdesse a diretriz (D5).

As condições de trabalho de enfermagem são historicamente determinadas pelo próprio processo de evolução social da enfermagem ${ }^{(24)}$, marcada pela influência da formação acadêmica dos enfermeiros ${ }^{(25)}$. Acreditamos que, na gerência, a produção social de significação aconteça como conseqüência da linguagem, dos hábitos, numa relação direta com os valores e práticas institucionais grupais.

A equipe de enfermagem como sustentáculo da unidade, constrói sua própria rede significações, operacionalizandoa, porém, esta não tem consciência do significado no que diz respeito a si própria e ao paciente. Dessa forma, possui condições suficientes para instituir e ressignificar sua prática à medida que for necessário ${ }^{(26)}$.

Nessa mesma via de reflexão, há a negação da dimensão social e das especificidades do trabalho do enfermeiro o que transparece não ter consciência nem de sua situação institucional nem de sua atuação no modelo. Assim, ele se insere no processo de trabalho com determinações que extrapolam funções predefinidas ou desejadas ${ }^{(23)}$.

Os enfermeiros gerentes entrevistados acreditam que são pessoas comprometidas, que auxiliam no desencadeamento das ações para a unidade. Sentem-se eficientes, pessoas que dispõe de um potencial para contribuir. Sentem-se valorizados e imaginam-se aceitos, porém admitem que pode haver exceções na aceitação. Também mencionam fatos e expressões e admitem que alguns os vêem como radicais, como pessoas que não deixam passar as coisas, presos aos cuidados com materiais e questões estruturais, insistentes naquilo que querem.

Os entrevistados justificam:

É na organização, no planejamento, nas decisões, enfim, associações que nós temos lá no básico. Ela é quem conduz. É a principal função além de fazer projetos, tentar fazer cursos, melhorar o serviço (D7).

A organização da unidade é a maior contribuição (D12).

Enquanto líder do grupo. Enfim, acho que na organização do grupo mesmo (D15). 
Na gerência, há predominância do caráter articulador e integrativo, ou seja,

a ação gerencial é determinada e determinante do processo de organização de serviços de saúde e fundamental na efetivação de políticas sociais e, em específico, nas de saúde ${ }^{(23)}$.

Convém notar que o procedimento que aparece nos relatos, intimamente ligado à representação do trabalho do gerente, de acordo com eles mesmos, é a organização do trabalho. Eles expressam sua vitalidade por meio de seus procedimentos na instituição. Essa reflexão sobre as práticas exercidas destaca uma construção cultural, portanto, por intermédio dos depoimentos vivificados, podemos elucidar algumas compreensões dos processos cognitivos e sociais, sem esquecer de levar também em consideração aspectos fundamentais da conduta humana, pois estes organizam as interpretações e as respostas para os eventos da prática gerencial do enfermeiro.

Assim, há necessidade de uma busca contínua por rupturas com espaços despotencializados para reivindicar acordos e negociações contributivos.

Autores entendem que

tomando a enfermagem em geral, ela é parte do trabalho em saúde, de forma que a assistência de enfermagem tem relações sociais com as outras práticas de saúde, que no conjunto complementam-se. Portanto, a enfermagem não desenvolve um trabalho autônomo, tanto no que se refere ao cuidar, quanto ao administrar, pois essa autonomia fica submetida a instâncias hierarquicamente superiores para administrá-lo e ao médico para o cuidado clínico, pois é ele que possui os instrumentos para diagnosticar e estabelecer ações terapêuticas, as quais direcionam parte significativa do cuidado em enfermagem ${ }^{(27)}$.

Tais práticas podemos associar à condução da tradição no evoluir da profissão, retomando as contribuições do trabalho do antropólogo ${ }^{(1)}$, quando se refere à Indonésia republicana após a revolução:

a sociedade como um todo, ela evoluiu e se desenvolveu, tornando-se finalmente talvez mais convencional e menos religiosa em seu temperamento.

Neste dizer, o autor ressalta o significado simbólico que as mudanças e as influências de transição conceptual da imagem clássica de uma comunidade pode assumir no que tange às influências do poder, dos significados ideológicos disseminados

Nesse sentido, os referenciais teóricos-ideológicos nos conduzem a perpetuações dos modelos advindos da organização cultural representada na profissão. Entretanto isso pode ser uma evidência das contradições atinentes ao diaa-dia do profissional na atividade gerencial, manifesto atra- vés dos conflitos cotidianos. Contudo, interrogamos: Estamos à procura de um novo arcabouço simbólico, na forma de pensar e reagir? Qual a concepção do gerente sobre o processo político instituído que é ideológico na profissão? Até que ponto ocorre sua sujeição a Deus, ao capital, ao Estado e à Instituição?

Notamos que, em função do envolvimento complexo no jogo das estruturas econômicas e políticas, o enfermeiro, ante a organização institucional hospitalar percebe que sua promoção ou exercício do cargo como gerente, vai até certo limite; então, entende que, a partir dali, ele se choca com detentores de poder em posições mais elevadas. Com essa tomada de consciência, o gerente traz à tona forças de repressão que permaneciam ocultas, ou menos visíveis quando nada o ameaçava. Dessa forma, o cargo traz à luz uma ameaça, incluindo também os demais participantes da categoria, tal percepção gera conflitos internos ao enfermeiro no cotidiano laboral.

Entendemos que, nesse momento, os pontos de referência de cultura como família, linguagem e formação profissional, deslocam-se, conduzindo-o a um distanciamento que produz uma identificação difícil, portanto geradora de angústia; pois, no papel de gerente, ele percebe o surgimento de novos poderes que, até então, não eram percebidos. Assim o profissional sente-se oprimido, sem forças e sem estratégias perante o contexto global, visto que suas forças estão dissipadas em múltiplas atividades que não correspondem ao interesse da sua categoria e menos ainda ao de seu objetivo soberano que é o de gerir o cuidado e cuidar da assistência à saúde.

Portanto, ao referirem-se as ações do exercício profissional, eles observam que apenas em parte elas correspondem ao que desejam, já que eles têm que associar a gerência com a assistência e tal associação se torna uma sobrecarga de trabalho. Na palavra deles:

É muito complicado. Tem manhã que eu sinto que eu não fiz nem uma coisa e nem outra, sabe. Já era complicado ser só assistencial com tantas atividades, agora então, dividindo com a gerência complicou mais, não é fácil (D17).

É uma saia justa, não é fácil. Às vezes é bem complicado, na realidade, eu tento me desdobrar, não é fácil, mas eu procuro estar presente no dia-a-dia e administrar o que eu tenho que administrar (D20).

A sobrecarga de trabalho e de tarefas até o limite do possível acontece, porque os enfermeiros se permitem assumir uma quantidade de trabalho superior à média, pois isso lhes fornece uma sensação benévola, de consciência tranqüila, de satisfação em prestar serviço, proporciona prazer, inicialmente. Com a perpetuação desse ritmo, chega a um ponto em que eles se esgotam pelos sacrifícios permanentes. Então, o profissional desmorona, manifestando seu sentimento via emoções: chorando, manifestando sua cen- 
sura aos demais, culpando-os por terem ficado com a melhor parte do trabalho e deixado para ele todo o sofrimento, ou demonstrando tensão nervosa, estresse e até hipertensão arterial, expressando, assim, sua situação de vítima, mergulhada em uma estrutura organizacional perversa.

Denotamos, pelos depoimentos, que a sobrecarga de trabalho diz respeito tanto ao aspecto psicológico como físico, pois a principal queixa fica velada pela falsa naturalização dos fatos, já que são ocultados os esforços dissipados para a execução das atividades, a fim de corresponder à imagem esperada. Dessa forma, banaliza-se o sofrimento do trabalhador gerente, o que diminui sua satisfação com o trabalho gerencial no cotidiano, uma vez que a rotina, as atividades mais simples, porém imprescindíveis, não são vistas, nem compartilhadas, nem valorizadas por seus pares; torna-se pesada para ele a incumbência do gerir.

A sobrecarga de trabalho na enfermagem, com freqüência, é mencionada, porém há indícios de que nem sempre está relacionada ao quantitativo de pessoal ${ }^{(19)}$. O presente estudo reafirma a associação do déficit de pessoal também a outros fatores adjuvantes.

Fica manifesto que a assistência é o foco do trabalho do enfermeiro, nele, o enfermeiro no qual expõe sua crença de que é resolutivo, competente, enfim, uma pessoa que resolve as diferentes e extremas situações. É evidente a dicotomia administração-assistência entre o desejado e o efetivado.

O exercício do cargo administrativo na instituição foi interpretado pelos depoentes de diferentes formas. Alguns vêem como normal o controle, porque existe uma hierarquia; porém não vêem como algo que os sufoquem. Boa parte mencionou e acredita que tem liberdade de atuação nas unidades; já, quanto à liberdade para exercer a atividade administrativa/gerencial, esta é restritiva, pois envolve o contexto da instituição sob uma visão do todo.

O agir nunca é controlável. Existe algo sempre por trás. Estamos na área do desejo (D11).

Estou nessa posição, eu tenho que saber que isso acontece: imprevistos, necessidades de telefonemas para soluções (D14)

O teor dos fragmentos apresentados dá mostras de que esses profissionais amparam a continuidade de uma relação de sujeição, enquanto dominados pelo mundo do trabalho, que os submetem aos jogos de poder que permeiam todo o sistema, assim, restringindo seu potencial. Acreditamos que esta perplexidade ante a massificação do trabalhador ocorre de maneira automática e pouco consciente.

Justificamos tal reflexão, retomando a afirmação de que o trabalho da enfermagem foi organizado sob três direções:

a primeira direção foi no sentido de organizar o cuidado ao doente, o que se deu pela sistematização das técnicas de enfermagem; a segunda, organizar o que se chama hoje um ambiente terapêutico por meio de mecanismos de purificação do ar, limpeza, higiene e outros; e a terceira, organizar os agentes de enfermagem por meio de seu treinamento, utilizando as técnicas e os mecanismos disciplinares ${ }^{(23)}$.

Assim, de certa forma, presumimos que existe uma intensa repercussão da história do desenvolvimento: da profissão médica, da de enfermagem, da institucionalização dos hospitais, no cotidiano profissional dos enfermeiros, uma vez que os conflitos gerados abrangem um aumento da violência interna - nas percepções dos entrevistados sobre o próprio trabalho - manifesto no corpo do(a) enfermeiro(a) gerente.

Ao discutirmos as relações de poder simbólico que se travam na organização do trabalho hospitalar, observamos que essas não se fundam somente nas relações interpessoais de influência ou domínio, mas revelam que as decisões são historicamente transmitidas, o que nos conduz a refletir sobre as considerações expressas pelos depoentes, visto que, entre estas, não há apenas uma oportunidade de escolha, há múltiplas. Dentre as opções, existem ilimitadas possibilidades. É possível dizer que as relações são constituídas historicamente, nelas, incorporam-se o saber da enfermagem associado às múltiplas dimensões. Com isso, percebe-se o atrelamento entre autonomia e dependência das relações imersas nas relações estruturais.

Ressaltamos que o contexto sócio-cultural vigente tolera a perversão e desta forma permite que ela se desenvolva. Neste emaranhado o poder não estabelece limites e descarrega responsabilidades sobre quem deveria orientar e ajudar e assim os sobrecarrega ${ }^{(28)}$.

Pelo exposto, podemos mencionar que o respeito, a escuta e a interação se processam, muitas vezes, de forma contraditória, submissa, como meio de realçar as disparidades e os poderes entre os diversos atores, a fim de se manter em um sistema que valoriza as aparências, as reticências, as máscaras, ou seja, que possibilita a perversão e o assédio nas relações cotidianas. Transparece, nos depoimentos, a escuta, o respeito, o diálogo como estratégias de enfrentamento a ser incorporada em nossa cultura, como mola propulsora de saída de uma situação obscura para uma possibilidade de visualização alternativa - de luz.

\section{CONCLUSÃO}

O exercício da gerência do enfermeiro é permeado de conflitos que podem ser interpretados pelos referenciais de cultura, como foi neste estudo, analisado segundo a Teoria Interpretativa da Cultura de Geertz.

Os resultados denotam a incorporação de elementos ideológicos que manifestam sua origem na forma de organização do trabalho, e reportam a idéia de lealdade às institui- 
ções, de talento, de reconhecimento, de valores relacionados à questão moral como: responsabilidade, disciplina, engajamento, harmonia, comprometimento, valorização do ser humano, que resultam em um sentimento que demonstra afinco com o caráter religioso e militar, o que justapõe alguns mitos, que servem de base à sua prática.

A condição para o exercício da gerência do enfermeiro é marcada pela incorporação de mecanismos de controle, conseqüentemente, de poder.

A gerência em enfermagem é um instrumento de trabalho fundamental para a efetivação de políticas, possibilitando construir um modelo assistencial alicerçado em valores adequados à cultura da própria profissão, organizado a partir da rede de saberes e das práticas que valorizam as multidimensões e a diversidade, para conseguir conviver, no cotidiano, com uma dinâmica complexa, alicerçada em contradições e paradoxos.

A representação do trabalho dos enfermeiros gerentes é a organização do trabalho. Eles expressam sua vitalidade por meio de seus procedimentos na instituição. Essa reflexão sobre as práticas exercidas destaca uma construção cultural, podendo elucidar algumas compreensões dos processos cognitivos e sociais, sem esquecer de levar também em consideração aspectos fundamentais da conduta humana, pois estes organizam as interpretações e as respostas para os eventos da prática gerencial do enfermeiro.

A gênese do conhecimento de administração na enfermagem efetiva-se com a organização da estrutura do ambiente e das técnicas para o cuidado. As relações de poder simbólico que se travam na organização do trabalho hospitalar não se fundam somente nas relações interpessoais no exercício da influência ou domínio, mas revelam que as decisões são historicamente transmitidas e incorporam o saber da enfermagem associado às múltiplas dimensões situadas mais nas relações estruturais.

Os resultados deste estudo apontam para a importância da cultura organizacional no exercício da gerência na enfermagem diante das incertezas laborais, na complexidade do ambiente hospitalar.

\section{REFERÊNCIAS}

1. Geertz C. A Interpretação das culturas. Rio de Janeiro: Livros Técnicos Científicos; 1989.

\section{Palmer RE. Hermenêutica. Lisboa: Edições 70; 1999.}

3. Geertz C. A mitologia de um antropólogo [Entrevista a Victor Aiello Tsu]. REVER Rev Estud Religião [periódico na Internet]. 2001 [citado 2004 jun. 17]; (3):[cerca de 8 p.]. Disponível em: http://www.pucsp.br/rever/rv3_2001/i_geertz.htm.

4. Geertz C. Nova luz sobre a antropologia. Rio de Janeiro: Jorge Zahar; 2001

5. Geertz C. Curriculum Vitae [text on the Internet]. Princeton; [cited 2004 Jun. 15]. Available from: http://www.sss.ias.edu/ community/faculty-cv/geertzcv.pdf.

6. Geertz C. Observando o Islã : o desenvolvimento religioso no Marrocos e na Indonésia. Rio de Janeiro : Jorge Zahar ; 2004.

7. Laplantine F. Aprender antropologia. São Paulo: Brasiliense; 2000.

8. Geertz C. O saber local: novos ensaios em antropologia interpretativa. Petrópolis: Vozes; 1997.

9. Pereira A, Erdmann AL. Pluralismo no cotidiano do espaço organizacional do enfermeiro. Texto Contexto Enferm. 1996; 5(2):147-55

10. Erdmann AL. Administração do processo de trabalho e da assistência de enfermagem. In: Santos I, organizadora. Enfermagem fundamental. São Paulo: Atheneu; 2001. p. 143-55.
11. Geertz C. A interpretação das culturas. Rio de Janeiro: Zahar; 1973.

12. Mondin B. O homem: quem é ele?. São Paulo: Paulus; 1980.

13. Cuche D. A noção de cultura nas ciências sociais. Bauru: EDUSC; 1999.

14. Pires MRGM. Enfermeiro com qualidade formal e política: em busca de um novo perfil [dissertação]. Brasília: Departamento de Serviço Social, Universidade de Brasília; 2001.

15. Conselho Nacional de Saúde. Resolução n. 196/96, de 10 de outubro de 1996. Dispõe sobre diretrizes e normas regulamentares de pesquisas envolvendo seres humanos. Bioética. 1996;4(2 Supl):15-25.

16. Silva GB. Enfermagem profissional: análise crítica. São Paulo: Cortez; 1986.

17. Barreira IA. A Enfermeira Anna Nery no "País do Futuro": a aventura da luta contra a tuberculose [tese]. Rio de Janeiro: Escola de Enfermagem Anna Nery, Universidade Federal do Rio de Janeiro; 1993.

18. Trevizan MA. Enfermagem hospitalar: administração \& burocracia. Brasília: Ed. UnB; 1988.

19. Sanna MC. Histórias de enfermeiras gerentes: subsídios para a compreensão de um modelo de referência de organização de serviços de enfermagem no período de 1950 a 1980 . Rio de Janeiro: Ed. Escola Anna Nery; 2002. 
20. Padilha MICS, Sobral VRS, Leite LMR, Peres MAA, Araújo AC. Enfermeira: a construção de um modelo de comportamento a partir dos discursos médicos do início do século. Rev Lat Am Enferm. 1997;5(1):25-33.

21. Carapinheiro G. Saberes e poderes no hospital. Porto: Afrontamento; 1998.

22. Deslandes SF. Frágeis deuses: profissionais da emergência entre os danos da violência e a recriação da vida. Rio de Janeiro: FIOCRUZ; 2002.

23. Almeida MCP, Rocha JSY. O saber de enfermagem e sua dimensão na prática. São Paulo: Cortez; 1989.

24. Carvalho V, Paim L. Acerca da assistência de enfermagem: considerando significado e destaques. Esc Anna Nery Rev Enferm. 1999;3(3):37-51.
25. Machado VB, Kurcgant P. O processo de formação de cultura organizacional em hospital filantrópico. Rev Esc Enferm USP. 2004;38(3):280-7.

26. Lenardt MH. A hospitalização desnudando o microcosmo de uma unidade hospitalar [tese]. Florianópolis: Centro de Ciências da Saúde, Universidade Federal de Santa Catarina; 2001.

27. Silva EM, Gomes ELR, Anselmi ML. Enfermagem: realidade e perspectiva na assistência e no gerenciamento. Rev Lat Am Enferm. 1993;1(1):59-63.

28. Hirigoyen M. Assédio moral: a violência perversa no cotidiano. Rio de Janeiro: Bertrand Brasil; 2003. 